\title{
ANALISIS STRATEGI RENCANA PEMBANGUNAN PETERNAKAN KAMBING PADA LAHAN PASCA TAMBANG (STUDI KASUS DI TELAGA BATU ARANG PT. KALTIM PRIMA COAL KABUPATEN KUTAI TIMUR)
}

\section{(Strategy Analysis of Goat Farming Development Plan in Post Mining Field (Case Study Telaga Batu Arang, PT Kaltim Prima Coal)}

\section{Joni Ariansyah, Ana Fitriah, Imam Sanusi}

Sekolah Tinggi Pertanian (STIPER) Kutai Timur

J1. Soekarno Hatta No. 1 Sangatta Utara Kab. Kutai Timur, Kalimantan Timur, Indonesia Email:joni_hublu@yahoo.com

Article Submitted : 18-5-2020

Article Accepted : 04-6-2020

\begin{abstract}
Coal mining concession area of PT. Kaltim Prima Coal is 90.938 ha. Some post-mining transition areas was used as a utilization zone for the development of agribusiness sectors such as livestock. The objective of the research was to analyze the strategy of development of goat farm in post-mining land. The method used was SWOT analysis that is systematic factor in determining company strategy for goat farm development plan. The result of SWOT analysis showed that the strategy of development of goat farm was in quadrant 1 in coordinate 3,250 (Internal Factor Evaluation) and 2,661 (External Factor Evaluation) external internal matrix. There was 6 (six) strategies that can be used as a reference for the development of goat farming by the company. Goat farming development plans can be implemented according to the results of the SWOT matrix that was grown and built, with the greatest potential being the availability of land and forage.
\end{abstract}

Keywords: farming goat, post mining, SWOT.

\section{PENDAHULUAN}

Wilayah Kabupaten Kutai Timur, Kalimantan Timur seluas 3.334.620,28 ha. Lahan pertambangan seluas 22.410,51 ha. Sumber pertambangan dan sumber daya perkebunan pertanian menjadi penompang terbesar pendapatan kabupaten Kutai Timur. Penduduk wilayah berjumlah 319.394 jiwa. Sektor pekerjaan utama penduduk adalah pekerja tambang dan perkebunan (BPS, 2017).

Tambang terbesar yang ada di Kabupaten Kutai Timur adalah PT. Kaltim Prima Coal (KPC). Total luasan area pertambangan PT. KPC sebesar 90.938 ha, sekitar $16 \%$ atau baru 14 ribu ha telah ditambang. Akhir tahun 2007, PT. KPC telah melakukan rehabilitasi seluas 2800 ha dan tahun 2009 telah dilakukan rehabilitasi seluas 3733 ha, hingga akhir 2011 sekitar 4500 ha sudah direklamasi. PT. KPC memperkirakan dari 90.938 ha total areal pertambangan, hanya 30 ribu ha yang dieksploitasi sampai akhir tahun 2021 (Ariansyah, 2016).

Pemanfaatan lahan reklamasi dilakukan PT. KPC untuk mengembangkan kegiatan kegiatan di sektor agribisnis. Salah satu program adalah pembangunan peternakan sapi terpadu (PESAT) sebagai wujud pengelolaan dan pemanfaatan lahan pasca tambang. Ariansyah (2016) 
menyatakan bahwa perusahaan tambang di Indonesia melakukan reklamasi lahan bekas tambang hanya sampai tahap penanaman atau penghijauan. Namun lahan bekas tambang yang sudah direhabilitasi dengan penghijauan tersebut dapat dimanfaatkan untuk program lain yang lebih produktif, misalnya pada sektor peternakan. Potensi tersebut juga dapat dimanfaatkan sebagai pengembangan ternak ruminansia lain, seperti kambing.

Telaga Batu Arang (TBA) merupakan salah satu pemanfaatan lahan bekas tambang yang difokuskan pada kawasan konservasi dan ekowisata. Program ini terdiri dari beberapa aspek salah satunya adalah pengembangan klaster hewani. Salah satunya rencana pembangunan peternakan kambing. Hal tersebut didukung dengan tanaman hijauan makanan ternak (HMT) yang terdapat di TBA sebagai perealisasian pembangunan peternakan kambing berbasis wilayah ex-tambang.

Dilihat dari aspek ekonomi pasar kambing sangat menjanjikan dibuktikan dengan permintaan kambing dan daging dari tahun ke tahun yang tinggi. Menurut BPS Kaltim (2017) bahwa produksi daging kambing di Kalimantan Timur tahun 2015 sebesar 441,36 ton dan 2016 naik menjadi 504,23 ton. Selain itu, pola budaya yang terkait dengan hari raya Qurban umat agama islam, menuntut ketersediaan kambing dalam jumlah yang cukup banyak.

Namun ketersediaan populasi kambing di Kutai Timur masih sedikit dan belum mampu memenuhi permintaan pasar. Hal tersebut dapat mendukung visi misi Pemerintah Kabupaten Kutai Timur, yaitu perwujudan agribisnis dan agroindustri.
Berdasarkan potensi yang ada perlu dilakukan analisis strategi rencana pembangunan kambing di lahan pasca tambang sebagai usaha peternakan yang berkelanjutan.

\section{METODE PENELITIAN}

Penelitian dilaksanakan pada bulan Februari - April 2018 di Telaga Batu Arang (TBA) PT. Kaltim Prima Coal dan Laboratorium Teknologi Hasil Ternak Sekolah Tinggi Pertanian Kutai Timur, Sangatta, Kalimantan timur. Metode pengumpulan data menggunakan kuesioner, wawancara, observasi dan studi pustaka. Data yang digunakan dari penelitian ini adalah data kualitatif dan kuantitatif berdasarkan hasil kuesioner dan wawancara. Jenis data yang digunakan adalah data primer dan data sekunder. Data primer berasal dari hasil wawancara langsung dengan beberapa stakholder, sedangkan data sekunder berasal dari buku-buku laporan dan lain-lain yang berasal dari instansi terkait dengan penelitian ini. Metode pengolahan dan analisis data yang digunakan adalah dengan pendekatan konsep manajemen strategis. Data dan informasi yang terkumpul diolah dan dianalisa secara kualitatif dan kuantitatif untuk memperoleh alternatif strategi bagi perusahaan. Metode yang digunakan yaitu metode SWOT, yaitu dengan mengumpulkan data kekuatan, kelemahan, peluang, dan ancaman terkait dengan strategi pengembangan usaha peternakan kambing di lahan pasca tambang. Berikut ini tahapan metode SWOT yang digunakan dalam penelitian ini. 


\section{Tahapan metode analisis SWOT}

Tahap pengumpulan data

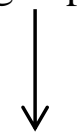

Tahap pengidentifikasian faktor internal dan eksternal

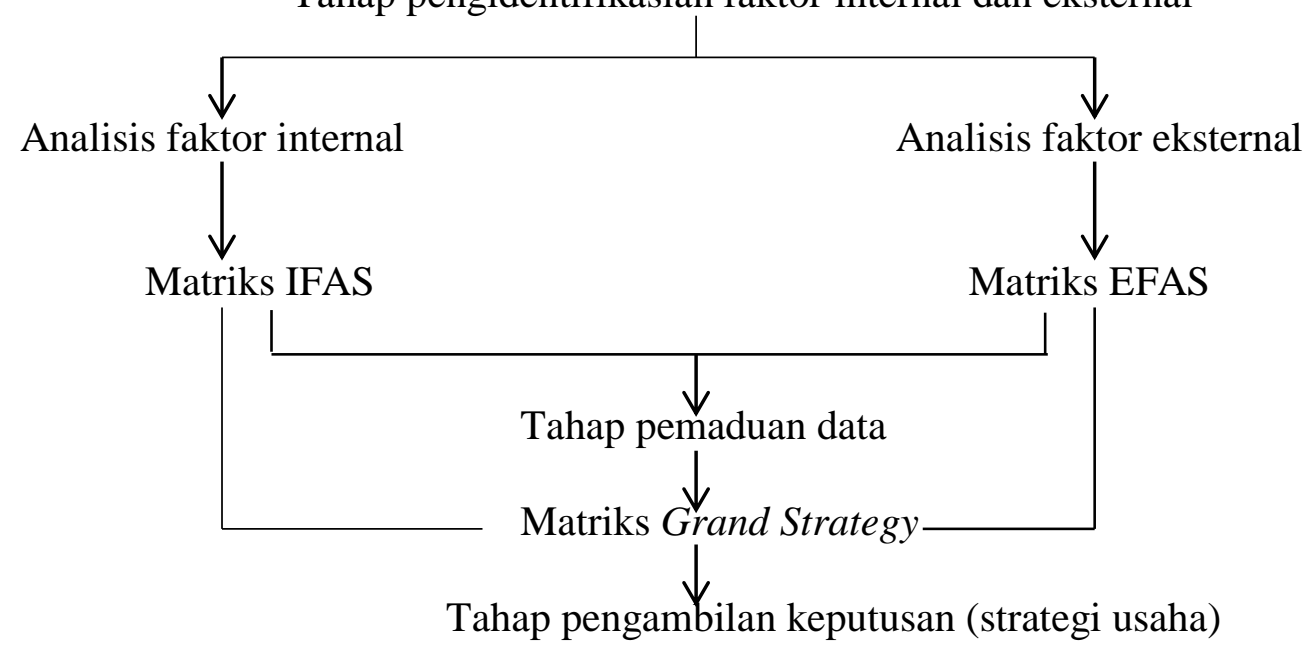

Gambar 1. Tahapan Analisis SWOT (Sumber: Rangkuti, 2000)

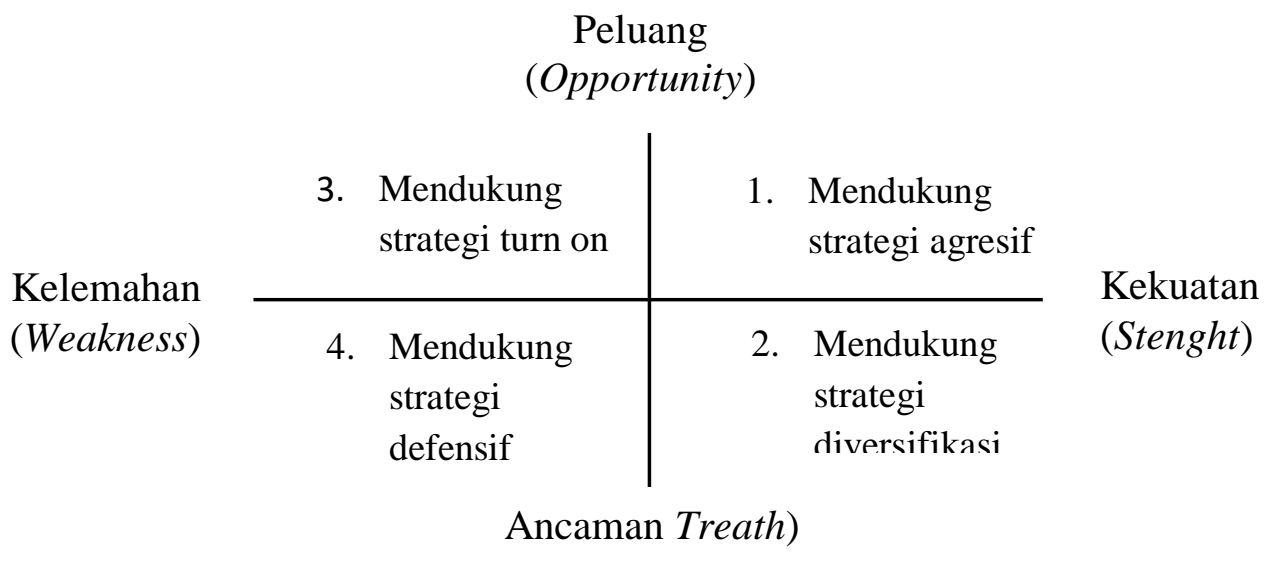

Gambar 2. Analisis Kesimpulan SWOT (Sumber: Rangkuti, 2000)

\section{HASIL DAN PEMBAHASAN}

Analisis SWOT adalah analisis yang digunakan dalam menentukan dan merumuskan strategi usaha agar usaha tersebut dapat terus berlangsung serta berkelanjutan. Analisis ini dengam memaksimalkan segala kekuatan, kelemahan, peluang dan ancaman. Analisis data akhir menggunakan matriks SWOT yang dibagai dalam 4 kuadran yaitu pertama strategi SO membuat strategi dengan memanfaatkan seluruh kekuatan untuk merebut dan memanfaatkan peluang sebesar - besarnya, kedua strategi ST strategi dalam menggunakan kekuatan yang dimiliki untuk mengatasi ancaman, ketiga strategi WO berdasarkan pemanfaatan peluang yang ada dengan cara meminimalkan kelemahan yang ada, keempat strategi WT didasarkan pada kegiatan yang bersifat defensif dan berusaha meminimalkan kelemahan yang ada serta menghindari ancaman (Rangkuti, 2000). 
Identifikasi faktor internal (kekuatan dan kelemahan) diperoleh dengan cara wawancara dan diskusi kepada pihak kepala bidang serta teknisi PT. KPC. Selain itu penentuan faktor yang menjadi kekuatan dan kelemahan juga diperoleh dengan cara membandingkan faktor yang ada dengan pelaku usaha pesaing.

Tabel 1. Kekuatan, kelemahan, peluang, dan ancaman PT. Kaltim Prima Coal

\begin{tabular}{ll}
\hline Peluang (Opportunity) & Kekuatan (Strenght) \\
1. Permintaan Ternak Kambing Tinggi & 1. Ketersediaan Modal \\
2. Rata-rata Penduduk Kutai Timur Beragama Islam & 2. Sumber Daya Manusia memadai \\
3. Jumlah Peternak Budidaya Kambing Rendah & 3. Jenis dan Produksi Hijauan \\
4. Pasar Kambing Tinggi & 4. Luas Lahan Tersedia \\
\hline Ancaman (Threat) & 5. Jauh Dari Permukiman Warga \\
1. Penutupan PT. Kaltim Prima Coal & Kelemahan (Weakness) \\
& 1. Program hanya sebagai Percontohan \\
\hline Sumber: Data Primer, 2018 & 2. Kesuburan Tanah Yang Rendah
\end{tabular}

Sumber : Data Primer, 2018

\section{Tahapan Strategi Pengembangan Usaha Tahap Masukan (The Input Stage)}

Pada tahap input, data yang dikumpulkan dianalisis kemudian dibedakan menjadi faktor internal dan faktor eksternal. Faktor-faktor yang didapatkan dari analisis lingkungan internal kemudian dijabarkan dalam matriks IFE (Internal Factor Evaluation), sedangkan faktor-faktor yang didapatkan dari analisis lingkungan eksternal dijabarkan dalam matriks EFE (External Factor Evaluation).

\section{Matriks IFE (Internal Factor Evaluation)} Matriks IFE (internal factor evaluation) diperoleh dari hasil identifikasi terhadap faktor internal perusahaan yang meliputi kekuatan dan kelemahan bagi strategi rencana pembangunan peternakan kambing PT. Kaltim Prima Coal. Matriks IFE disusun dengan pemberian rating dan pembobotan. Dari hasil pembobotan dan penentuan rating, maka dapat diperoleh nilai IFE yang dapat dilihat pada tabel 2 . Responden yang dijadikan rujukan dalam penentuan faktor IFE adalah koordinator CAD (conservetion and agribussnies development), koordinator PMD (post minning development) dan teknisi lapangan PT. Kaltim Prima Coal.

Tabel 2. Internal Factor Evaluation (IFE)

\begin{tabular}{lccc}
\hline \multicolumn{1}{c}{ Faktor Internal } & Bobot & Rating & Skor \\
\hline Kekuatan & & & 0.572 \\
1. Ketersediaan Modal & 0.143 & 4 & 0.568 \\
2. Ketersediaan Sumber Daya Manusia & 0.142 & 4 & 0.426 \\
3. Jenis dan Produksi Hijauan & 0.142 & 3 & 0.471 \\
4. Luas lahan tersedia & 0.157 & 3 & 0.426 \\
5. Jauh dari permukiman & 0.142 & 3 & 0.284 \\
\hline Kelemahan & & 2 & 0.282 \\
1. Program hanya sebagai Percontohan & 0.142 & 2 & 3.029 \\
2. Kesuburan Tanah Lahan Pasca Tambang & 0.141 & & \\
$\quad$ Rendah & & & \\
\hline Sotal & & & \\
\hline Sumber : Data Primer, 2018 & & & \\
\end{tabular}

Berdasarkan hasil pembobotan dan pemberian rating, maka diperoleh nilai IFE yang dapat dilihat pada Tabel 2. Total skor faktor strategis internal adalah 3,029. Nilai tersebut menunjukkan strategi rencana pembangunan peternakan kambing PT. Kaltim Prima Coal berada pada rata-rata nilai kekuatan internal secara keseluruhan baik. Nilai skor total untuk kekuatan adalah 2,463 dan skor total untuk kelemahan adalah 
0,566. Nilai akhir skor total kekuatan yang lebih besar dari kelemahan menunjukkan bahwa dalam strategi pengembangan peternakan kambing PT. Kaltim Prima Coal mampu memanfaatkan kekuatan yang dimiliki dan mampu mengatasi kelemahan yang ada. Pada Tabel 2. dapat dilihat kekuatan terbesar pada strategi pengembangan peternakan PT. Kaltim Prima Coal adalah modal usaha yang besar dengan skor total tertinggi 0,572. Modal usaha yang besar merupakan kekuatan terpenting dalam strategi rencana pembangunan usaha atau dalam merintis usaha sebagai pemula karena semua usaha titik tumpunya pada modal itu sendiri. Diketahui bahwa PT. Kaltim Prima Coal memiliki dana CSR (Corporate Social Responbility) yang salah satunya dialokasikan untuk pengembangan lahan pasca tambang. Kekuatan utama ini sangat dibutuhkan dalam menjalankan usaha karena modal usaha membantu keberlasungan dan keberlanjutan serta akan membantu perusahaan dalam mencapai visi dan misi. Sementara itu kelemahan utama pada strategi rencana pemabngunan peternakan kambing PT. Kaltim Prima Coal adalah program hanya sebagai percontohan dengan bobot skor 0,284. Program tersebut adalah program yang dijalankan perusahaan sebagai percontohan dan analisis manfaat lahan pasca tambang sebagai peternakan kambing. Kelemahan tersebut dapat diatasi dengan kekuatan - kekuatan perusahaan untuk menjalankan usaha secara berkelanjutan dan profitable.

\section{Matriks EFE (External Factor Evaluation)}

Matriks EFE diperoleh dari hasil identifikasi terhadap faktor eksternal yang meliputi peluang dan ancaman bagi strategi pengembangan peternakan kambing PT. Kaltim Prima Coal. Matriks EFE disusun dengan pemberian rating dan pembobotan. Dari hasil pembobotan dan penentuan rating, maka dapat diperoleh nilai EFE yang dapat dilihat pada tabel 3. Matriks EFE diperoleh dari hasil identifikasi terhadap faktor eksternal yang meliputi peluang dan ancaman bagi strategi pengembangan peternakan kambing PT. Kaltim Prima Coal. Matriks EFE disusun dengan pembobotan dan pemberian rating. Dari hasil pembobotan dan penentuan rating, maka dapat diperoleh nilai EFE yang dapat dilihat pada Tabel 3.

Tabel 3. Eksternal Factor Evaluation (EFE)

\begin{tabular}{lccc}
\hline \multicolumn{1}{c}{ Faktor Eksternal } & Bobot & Rating & Skor \\
\hline Peluang & & & 0.796 \\
1. Permintaan ternak kambing yang tinggi & 0.199 & 4 & 0.800 \\
2. Rata - Rata Penduduk Kutai Timur Beragama & 0.200 & 4 & 0.796 \\
$\quad$ Islam & & 4 & 0.597 \\
3. Jumlah Peternak Budidaya Kambing Relatif & 0.199 & 3 & 0.597 \\
$\quad$ Rendah & 0.199 & 3.586 \\
4. Pasar kambing tinggi & & 3 &
\end{tabular}

Total skor faktor strategis eksternal adalah 3,586. Skor merupakan nilai bobot dikalikan dengan rating. Nilai tersebut menunjukkan bahwa strategi pengembangan peternakan kambing PT. Kaltim Prima Coal memiliki peluang yang besar dan dapat mengatasi ancaman dengan peluang tersebut. Skor total untuk peluang adalah
3,169 dan skor total untuk ancaman adalah 0,597. Nilai tersebut menunjukkan bahwa responden serta pengamatan lapangan memberikan respon positif lebih terhadap faktor peluang dan respon negatif yang kecil terhadap faktor ancaman.

Tabel nilai peluang terbesar dengan skor total 0,800 adalah rata - rata penduduk 
Kutai Timur beragama muslim. Rata - rata penduduk Kutai Timur beragama Islam yaitu 338.505 jiwa. Hal tersebut adalah peluang yang baik bagi upaya pencapaian misi dan visi perusahaan dalam rencana pembangunan usaha peternakan kambing di Sangatta. Mayoritas penduduk yang beragama muslim melakukan acara keagamaan seperti idul Adha dan Aqiqah merupakan hal terpenting dalam peningkatan kebutuhan serta penyediaan kambing di Sangatta. Hal ini berdasarkan data BPS Kaltim dalam angka (2017) bahwa produksi daging kambing pada tahun 2016 di Kab. Kutai Timur mencapai 50,07 ton dengan rata - rata produksi daging kambing di Kalimantan Timur per tahun adalah 571,088 ton.

Data tabel 3. ancaman terbesar bagi strategi rencana pembangunan peternakan kambing PT. Kaltim Prima Coal adalah penutupan PT. Kaltim Prima Coal dengan bobot skor 0,597. Penutupan PT. Kaltim Prima Coal berpengaruh pada usaha - usaha yang dijalankan di area pasca tambang. Perubahan peraturan wilayah pertambangan yang tertera di UU Minerba dan peraturan pemerintah merupakan salah satu dampak pembangunan usaha peternakan kambing tersebut dapat berlanjut atau berhenti. Program - program pasca tambang yang telah dilakukan saat ini berdasarkan izin pertambangan PT. KPC yang masih aktif menambang batubara. Adanya ancaman tersebut dapat membantu perusahaan dalam menyusun strategi pengembangan peternakan kambing yang tepat bagi perusahaan. Faktor ancaman dapat dihindari atau dihadapi dengan alternatif strategi yang dibuat sesuai dengan kondisi perusahaan saat ini. Matriks EFE (Eksternal Factor Evaluation) membantu perusahaan dalam menentukan alternatif strategi yang tepat sesuai dengan kondisi lingkungan perusahaan saat ini maupun dimasa yang akan datang.

\section{Matriks SWOT}

Tahap sebelumnya matriks IFE dan EFE pada tahap penentuan nilai, kemudian dilanjutkan matriks SWOT yang digunakan pada strategi alternatif pengembangan usaha tersebut. Berdasarkan kekuatan, kelemahan, peluang, dan ancaman yang diperoleh melalui analisis internal dan eskternal, maka dapat diformulasikan strategi alternatif pengembangan peternakan kambing dengan menggunakan matriks SWOT. Beberapa strategi alternatif yang dapat diterapkan pada strategi pengembangan peternakan kambing PT. Kaltim Prima Coal dapat dilihat pada Tabel 4.

\section{Tabel 4. Matrik SWOT}

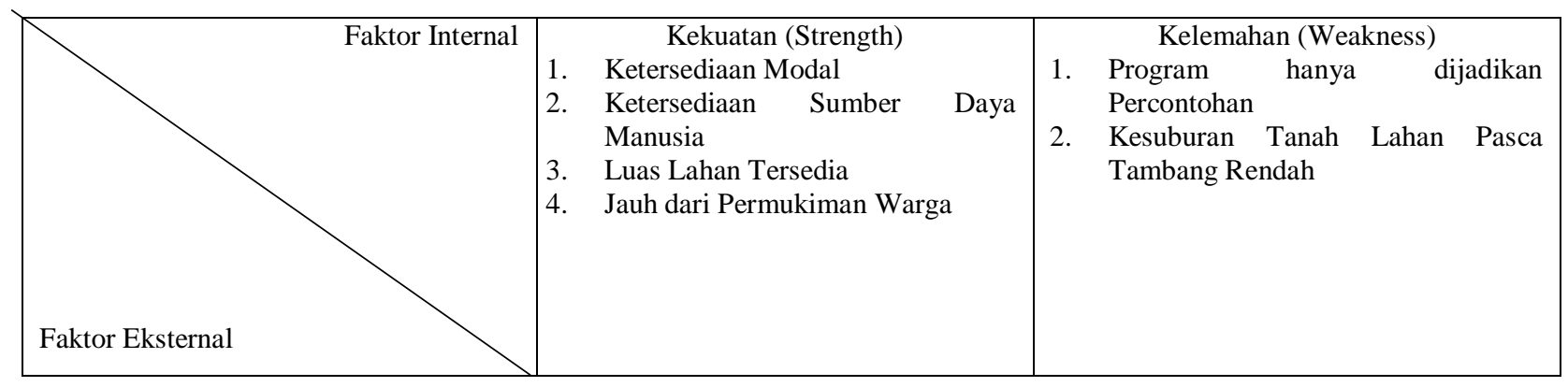




\begin{tabular}{|c|c|c|}
\hline $\begin{array}{l}\text { Peluang (Opportunity) } \\
\text { 1. Permintaan Ternak Kambing yang } \\
\text { Tinggi } \\
\text { 2. Rata - Rata Penduduk Kutai Timur } \\
\text { Beragama Islam } \\
\text { 3. Jumlah Peternak Budidaya } \\
\text { Kambing Relatif Rendah } \\
\text { 4. Pasar Kambing Tinggi }\end{array}$ & $\begin{array}{l}\text { 1. Membangun peternakan kambing } \\
\text { berbasis breeding / budidaya } \\
\text { penggemukkan kambing untuk } \\
\text { memenuhi kebutuhan kambing } \\
\text { lokal } \\
\text { 2. Memaksimalkan luas lahan pasca } \\
\text { tambang untuk pembangunan } \\
\text { peternakan kambing sesuai target } \\
\text { pasar }\end{array}$ & \begin{tabular}{l}
\multicolumn{3}{c}{$\mathbf{W}-\mathbf{O}$} \\
1. Memanfaatkan peluang usaha \\
dengan bekerjasama atau sharing \\
dengan peternak kambing yang ada \\
di Sangatta \\
2. Mendirikan dan membangun usaha \\
peternakan kambing yang \\
berkelanjutan guna memenuhi \\
kebutuhan kambing lokal Sangatta
\end{tabular} \\
\hline $\begin{array}{l}\text { Ancaman (Treath) } \\
\text { 1. Penutupan PT. Kaltim Prima Coal }\end{array}$ & $\begin{array}{l}\text { S. S } \\
\text { 1. Melakukan analisis kelayakan } \\
\text { usaha pembangunan peternakan } \\
\text { jangka pendek untuk menghindari } \\
\text { dampak penutupan tambang. }\end{array}$ & 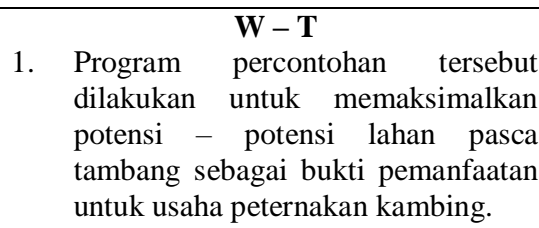 \\
\hline
\end{tabular}

Strategi S-O (Strength - Opportunity)

1. Membangun Peternakan Kambing Berbasis Breeding/Budidaya Penggemukkan Kambing untuk Memenuhi Kebutuhan Kambing Lokal

Strategi ini digunakan dengan melihat kekuatan dan peluang yang dimiliki oleh perusahaan. Peluang besar dari perusahaan adalah permintaan kambing yang masih tinggi. Dalam hal ini kenaikan permintaan yang signifikan terjadi pada hari raya Qurban. Kekuatan perusahaan seperti luas lahan dan potensi hijauan dapat menjadi suatu peluang usaha dalam pembangunan peternakan kambing. Kebutuhan kambing belum dapat terpenuhi dengan adanya pola breeding yang akan dibangun. Permasalahannya adalah bagaimana memanfaatkan potensi sumberdaya alam, kambing, sumberdaya manusia, pasar dan penunjang secara optimal agar pengembangan kambing dapat direalisasikan secara maksimal (Djajanegara dan Misniwaty, 1998).

2. Memaksimalkan Luas Lahan Pasca Tambang untuk Pembangunan Peternakan Kambing Sesuai Target Pasar

Luas lahan pasca tambang memiliki potensi untuk pembangunan peternakan. Lahan pasca direvegetasi dengan hijauan. Revegetasi di lahan reklamasi PT. KPC diutamakan kepada stabilitas tanah dan menurunkan tingkat erosi penambangan dengan penanaman rumput pakan seperti hijauan makanan ternak maka, lahan tersebut dapat dimanfaatkan sebagai padang penggembalaan sapi (Daru, 2009).

\section{Strategi W-O (Weakness - Opportunity)}

1. Memanfaatkan peluang usaha dengan bekerjasama atau sharing dengan peternak kambing yang ada di Sangatta

Sharing tersebut bertujuan untuk melakukan kajian tentang pemeliharan ternak kambing yang sesuai dengan kondisi lingkungan di daerah Sangatta. Kebutuhan lain misalnya pakan yang merupakan salah satu kebutuhan vital bagi ternak dimana menjadi sumber kebutuhan maintenance dan produksi. Melihat kondisi curah hujan di Sangatta yang dapat memenuhi kebutuhan air dalam tanah dan menumbuhkan berbagai hijauan. Kerjasama berikutnya yaitu ternak kambing dalam bentuk bibit kambing yang dapat dirotasi dengan peternak untuk memenuhi kebutuhan ternak kambing di Sangatta. Strategi pemberdayaan peternak tidak hanya dilakukan oleh pemerintah tetapi juga melibatkan peternak itu sendiri dan pihak swasta dengan melakukan kerjasama yang saling menguntungkan (Siregar, 2012).

2. Mendirikan dan membangun usaha peternakan kambing yang berkelanjutan guna memenuhi kebutuhan kambing lokal Sangatta 
Potensi ekonomi daerah didefinisikan sebagai kemampuan ekonomi yang ada di daerah yang mungkin dan layak dikembangkan sehingga akan terus berkembang menjadi sumber penghidupan rakyat setempat bahkan dapat mendorong perekonomian daerah secara keseluruhan untuk berkembang dengan sendirinya dan berkesinambungan (Suparmako, 2002). Usaha peternakan kambing di lahan pasca tambang ini diharapakan akan menjadi salah satu kekuatakan ekonomi masyarakat pasca tambang nanti. Kenyataannya usaha peternakan kambing yang akan perusahaan lakukan adalah usaha peternakan bertipe percontohan. Kelemahan ini seharusnya dapat dianalisis ulang dalam membangun usaha peternakan dimana jika usaha tersebut dapat berkelanjutan dan dapat memenuhi kebutuhan kambing di Sangatta perusahaan akan dinilai positif dalam memanfaatkan lahan bekas tambang secara optimal. Peluang seperti ini harus perusahaan perhatikan untuk mengatasi kelemahan yang ada di dalam perusahaan. Hal ini juga sesuai pendapat Kariyasa (2005) tentang sapi potong, bahwa usaha budidaya mendukung upaya ketahanan pangan, baik sebagai penyedia bahan pangan maupun sebagai sumber pendapatan yang keduanya berperan meningkatkan ketersediaan dan aksesibilitas pangan.

\section{Strategi S-T (Strength - Treath)}

Melakukan Analisis Kelayakan Usaha Pembangunan Peternakan Jangka Pendek untuk Menghindari Dampak Penutupan Tambang. Analisis usaha dilakukan bertujuan untuk menganalisis usaha jangka pendek dapat mengutungkan atau merugikan. Tujuan lain dari analisis kelayakan usaha adalah mengetahui kemampuan usaha pembangunan kambing agar dilaksanakan berkelanjutan. Semua faktor dari kekuatan dibuktikan hasilnya untuk menutupi ancaman dari luar. Hal ini sesuai pendapat Suliyanto (2010) yang mengatakan bahwa studi kelayakan usaha dilakukan dengan tujuan apakah usaha dapat dilanjutkan atau tidak dilanjutkan. Analisis usaha juga terkait dengan analisis manfaat yang sangat penting dilakukan. Kegunaan analisis manfaat bagi perusahaan tidak terbatas pada meningkatnya kinerja perusahaan, transparansi dan akuntabilitas, namun menjadi alat evaluasi dan pembelajaran bagi organisasi, dan perbaikan yang sistematis bagi media komunikasi dengan stakeholder (Irawaty, 2008).

\section{Strategi W-T (Weakness - Treath)}

Program Percontohan Tersebut Dilakukan untuk Memaksimalkan Potensi - Potensi Lahan Pasca Tambang sebagai Bukti Pemanfaatan untuk Usaha Peternakan Kambing

Total lahan reklamasi di telaga batu arang sebagian akan dibangun dan dikembangkan usaha peternakan diatas lahan pasca tambang. Program percontohan pemanfaatan lahan bekas tambang untuk usaha pengembangan sapi telah dilakukan PT. KPC dalam bentuk Peternakan Sapi Terpadu atau PESAT (Ariansyah et. al., 2014). Program percotohan peternakan kambing nantinya harus mampu mencapai target yang sesuai dari program sebelumnya dalam hal ini pengembangan PESAT. Upaya - upaya dalam perencanan pembangunan peternakan kambing harus memperkecil segala dampak buruk usaha tersebut. Lahan bekas tambang dapat direklamasi dan dimanfaatkan menjadi tempat rekreasi, waduk, kolam ikan, perumahan, perkebunan atau revegetasi saja (kombinasi tanaman hutan atau pioner, tanaman buah, covercropp), pertanian dan peternakan. Lahan bekas tambang juga bisa direstorasi, dikembalikan ke bentuk penggunaan semula, misalnya kawasan hutan lindung (Wardoyo, 2008).

\section{KESIMPULAN}

1. Membangun peternakan kambing berbasis breeding atau budidaya penggemukkan kambing untuk memenuhi kebutuhan kambing lokal 
2. Memaksimalkan luas lahan pasca tambang untuk pembangunan peternakan kambing sesuai target pasar

3. Memanfaatkan peluang usaha dengan bekerjasama atau sharing dengan peternak kambing yang ada di Sangatta

4. Mendirikan dan membangun usaha peternakan kambing yang berkelanjutan guna memenuhi kebutuhan kambing lokal Sangatta

5. Melakukan analisis kelayakan usaha pembangunan peternakan jangka pendek untuk menghindari dampak penutupan tambang

6. Program percontohan tersebut dilakukan untuk memaksimalkan potensi - potensi lahan pasca tambang sebagai bukti pemanfaatan untuk usaha peternakan kambing.

\section{Saran}

Berdasarkan simpulan hasil penelitian, maka saran yang dapat diberikan adalah dengan memaksimalkan segala kekuatan dan peluang yang dimiliki agar dapat membangun peternakan kambing yang berkelanjutan.

\section{DAFTAR PUSTAKA}

Badan Pusat Statistik Kabupaten Kutai Timur. 2017. Kabupaten Kutai Timur dalam Angka. Kutai Timur

Badan Pusat Statistik Kalimantan Timur. 2017. Kalimantan Timur dalam Angka. Kalimantan Timur.

Ariansyah, J., A. Ismail, \& L. Abdullah. 2014. Ex-Mining Land Use in the Livestock Sector for Sustainable Development : a Benefit Anaysis. Proceeding $1^{\text {st }}$ PIKSI International Conference on Knowledge and Sciences 2014. Bandung, 18-19 November 2014. Halaman 30.

Ariansyah, J. 2016. Potensi Pengembangan Usaha Peternakan Terpadu di Atas
Lahan Bekas Tambang pada PT. KPC Kutai Timur. Ziraa'ah Majalah Ilmiah Pertanian, Vol. 41 No. 2 (195-204).

Daru, T.P. 2009. Tehnik Pengembangan Tanaman Penutup Tanah pada Lahan Reklamasi Tambang Batubara Pastura. Disertasi repository.ipb.ac.id/. diakses pada tanggal 09 Mei 2017.

Djajanegara, A dan A, Misniwaty. 1998. Pengembangan Usaha Kambing dalam Konteks Sosial-Budaya Masyarakat. Populasi, Vol. 13 No. 5.

Irawaty, W. 2008. Analisis Cost Benefit Pelaksanaan Corporate Sosial Responsibility Program Bogasari Mitra Card Surabaya. Jurnal Akuntansi dan Teknologi Informasi, Vol 7. No.1, Mei 2008:26-40.

Kariyasa, K. 2005. Sistem Integrasi Tanaman Ternak dalam Perspektif Reorientasi Kebijakan Subsidi Pupuk dan Peningkatan Pendapatan Petani. Jurnal Analisis Kebijakan Pertanian $3(1): 68-80$.

Rangkuti, F. 2000. Analisis SWOT Teknik Membedah Kasus Bisnis, Reorientasi Konsep Perencanaan Strategis untuk Menghadapi Abad 21. PT. Gramedia Pustaka Utama. Jakarta.

Siregar, G. 2012. Analisis Kelayakan dan Strategi Pengembangan Usaha Ternak Sapi Potong. Agrium Volume 17 Nomor 3.

Suliyanto. 2010. Studi Kelayakan Bisnis; Pendekatan Praktis. Andi. Yogyakarta. 
Suparmoko, M. 2002. Ekonomi Publik untuk Keuangan dan Pembangunan Daerah. Andi. Yogyakarta.
Wardoyo, S.S. 2008. Reklamasi Lahan Bekas Tambang yang Berwawasan Lingkungan. Jurnal Agros Vol.10, No.1 Januari 2008:43-55. 